\title{
STUDY OF SEASONAL ACOUSTIC PROPERTIES OF SEA WATER IN SELECTED WATERS OF THE SOUTHERN BALTIC
}

\begin{abstract}
Climate Research of the globe is a current task, in particular to confirm the general hypothesis of global warming associated with an increase in average temperature. The sea acoustic climate is derived from the concept of climate and refers to the conditions of propagation of acoustic waves in a particular basin. In this paper, the results of systematic measurements of temperature, salinity and velocity distributions of sound in the area of the southern Baltic will be present. The focus will be on the results of extensive measurements carried out „in situ” in particular.
\end{abstract}

Keywords: sound propagation in sea water, acoustic climate of the Baltic Sea

\section{INTRODUCTION}

The increasing use of acoustic devices used for underwater research $[4,6,13,17]$, and the assessment of the seabed $[14,15]$ causes, that the general interest of acoustic climate of underwater observation is a challenge for hydro-acousticians. Detection of the underwater sound channel in the Atlantic Ocean during the period of the Second World War made the observations and the use of variable acoustic properties of seawater become the subject of constant observation. Of course, the study of acoustic properties of the Baltic Sea took place much later. The periodic occurrence of the acoustic channel in this basin was discovered by Hela [8]. It should be mentioned, that in the early seventies of the last century, research on the study of the acoustic properties of Baltic sea was carried out in Poland $[9,25,28]$. The presence of seasonal changes in the conditions of propagation of acoustic waves is one of the elements of the research - measurement work conducted in the area of the Southern Baltic. The results presented in this article have been developed mainly on the basis of measurement data collected during research cruises made by $\mathrm{r} / \mathrm{v}$ "Baltica".

The main premise of the publication is to present the results, which on one hand are retrospective, and on the other represent a period of time, which is part of the history of the acoustic climate of the South Baltic and can be used to determine the average acoustic parameters of the tested reservoir.

The authors interest is focused on three water regions of the South Baltic sea with a relatively large depth, namely: Bornholm Deep, Gdansk Deep and Slupsk Furrow. The study period is for selected months taken as representative for the respective season of 2005 .

\section{THE OCEAN ATMOSPHERE INFLUENCE AS A HYDROLOGICAL CONDITIONS SHAPE FACTOR OF THE BALTIC SEA}

The hydrological conditions of seas and oceans form the phenomena related to the interaction of the spheres of the Earth. Climate and weather on Earth are shaped by three basic climate-forming processes: heat circulation, water circulation and air circulation, as well as geographical factors: layout of land and oceans, the height above the sea level and distance from the sea (ocean).

In general, the climate of the southern Baltic is influenced much by the Atlantic Ocean and the continent of Eastern Europe [16, 18, 19, 21]. Terms of land around the Baltic Sea foster free reach of air masses from almost all directions over the sea, but when they go through the North Sea they again take on moisture. The humid air masses from the North Sea, which reach into the Baltic Sea from the west, cause the occurrence of precipitation. Continental air masses come unhindered from the east and south to the Baltic Sea. Only air masses coming from the north to the region of the Baltic Sea face an orographic natural barrier in the form of the Scandinavian Mountains. Therefore, the location of the Baltic sea favors frequent exchange of physically differing air masses. Consequently, this results in high variability of weather in a short period of time (overnight), as well as on an annual basis. This is exemplary confirmed by a sample forecast of the pressure system for tomorrow (30.11.2015) which promises fluctuations in weather as shown in Figure 1.

According to Koppen climate classification [12] the Baltic Sea is situated in the area of two types of climate: Cf - warm temperate with uniform soil moisture and Df - cold climate with uniform soil moisture (continental). The warm temperate 
strip covers the south waters of the Baltic Sea. On said area, the influence of the Atlantic climate due to the prevailing winds from the western direction carrying a mass of moist air temperate is shown. Characteristic of this climate is rain throughout the year, with the largest number of them is observed in summer and lowest in winter.

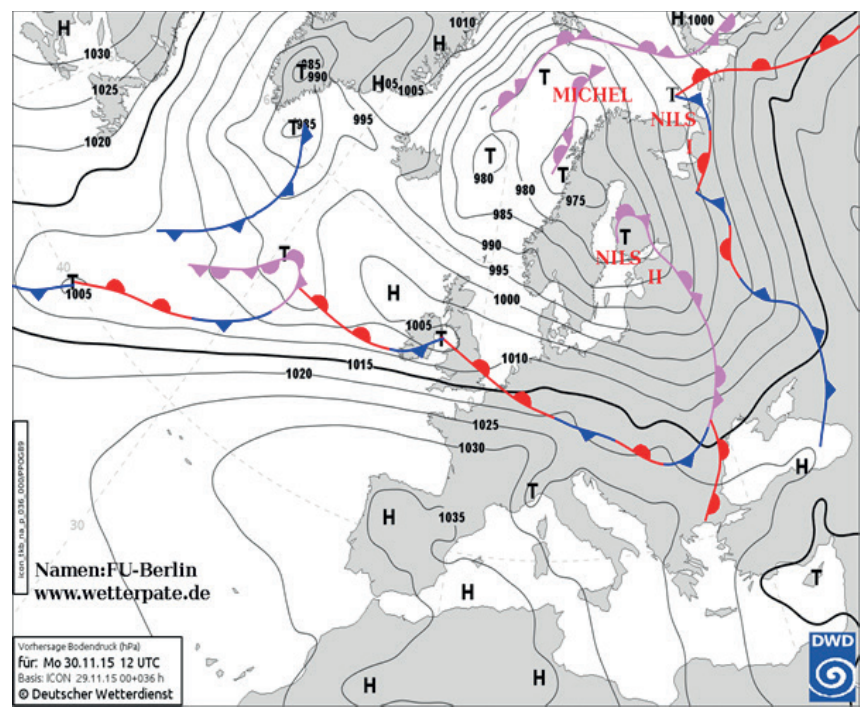

Fig. 1. Expected pressure system for Europe on 30 November 2015 [http://dobrapogoda.blog.pl/uklad-baryczny-nad-europa/]

For the Central Baltic region, the transition from marine to land climate is characteristic. A manifestation of this is the increase in daily temperature differences in the air as you move from the coast inland. In the area, winds from the eastern direction from NW to SW are prevailing, and the humidity is the highest in winter and lowest in May.

The continental climate area type Df extends over part of the Baltic Sea located to the north and east of the ÖlandKaliningrad line. Rainfall is present here in all seasons, most in August - September, and the least in March. In this area, the impact of marine climate is reduced and in the eastern part of the land climate impact increases.

The climate of the Baltic is determined by its position in two climate zones and the proximity of the Atlantic Ocean. Over the area of the Baltic Sea, in the summer come partly tropical air mass and in winter often come arctic and polar air mass. The influence of Atlantic air mass causes an increase in humidity, as well as warming in winter and cooling in summer.

\section{SEA WATER HARACTERISTICS CHANGES IN THE SELECTED WATERS OF THE SOUTHERN BALTIC SEA}

The acoustic environment of the Baltic Sea is very complicated, which results from a wide variety of factors that shape it: the geological structure of the bottom, bottom sediments and changes in temporal and spatial hydrological conditions. The possibility to use hydro acoustic devices to study the underwater Baltic Sea, as well as underwater communication directly depend on all these factors, with the most important changes are the thermo-halifax ones. The natural conditions of the Baltic Sea are described in detail in literature. Recently, 3 extensive monographs devoted to the Baltic sea have been published $[1,26,27]$. While reports characterizing the acoustic climate of the Baltic Sea in detail are rare $[10,5]$.

In literature, several reports of relationship between the conditions of propagation of acoustic waves, particularly sound velocity distributions, and spatial distributions of the temperature and salinity can be found. Usually, however, these publications are of a general nature $[11,22]$ or on experimental studies, which are fragmentary information on hydrological conditions and the acoustic measurements. For example, a summary of research on the measurement and simulation of transmission loss (propagation loss) in the Landsort Deep, the Gotland Deep and Bornholm Deep areas conducted in 2002-2007 are given in [3]. The existence of a sound channel creates favorable conditions for underwater communication, but its variability time-space significantly complicates these conditions [eg. 24]. Changes in distribution speed of sound in the basin, which for a short observing time, order of days, can be regarded as quasi-stationary, can be modified by the phenomenon of internal waves [23], mixing the wind [7] or the inflow of refueling water [20].

The nature of changes in the properties of seawater is significantly associated with the seasons, mainly because the effect of temperature mainly affects the characteristics of the physical-chemical properties of sea water. Of course, the content of variable salinity also impinge on the water characteristics and have slightly different character volatility [20]. The analysis covered the months of February and July, September and November. February represents the winter season, July and September represent summer and autumn in November. The results have been developed on the basis of the measurement data collected during research cruises made by $\mathrm{r} / \mathrm{v}$ "Baltica". Measurements of temperature and salinity were made with the use of Neil Brown CTD probe, and the acoustic wave velocity values were determined based on an empirical relationship linking the speed of sound hydrological parameters [2].

The evaluation of changes in acoustic conditions can be made by analyzing the velocity sound distributions on a hydrological profile at particular times of the year and comparing the imaged data with the values that characterize the different regions on the basis of long-term data. The following figures (Fig. 2 - Fig. 5) show the temperature, salinity, and consequently the speed of sound distribution changes in the course of the year in the cross section through the depths of the Southern Baltic for example, data from the year 2005, not distinguishing itself with any specific anomalies.

The use of perennial statistical data is helpful in the assessment of current acoustic situation. Tables 1-6 summarize the information about the temperature, salinity and sound velocity at the surface and at the bottom of the depth of the main southern Baltic sea. The tables show the values in 2005 
in individual months, and the arithmetic mean of the same parameters designated for a period of 50 years from 1960 to 2010 .
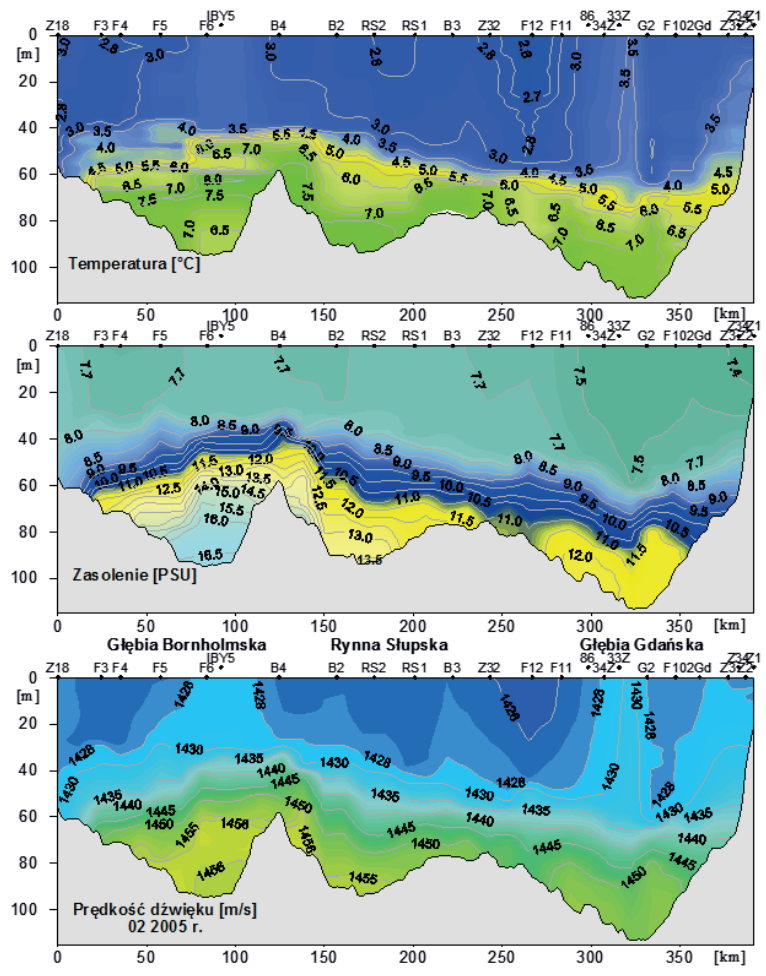

Fig. 2. Vertical distribution of temperature, salinity and sound velocity profile on the hydrological profile though the depths of the southern Baltic sea (February 2005)
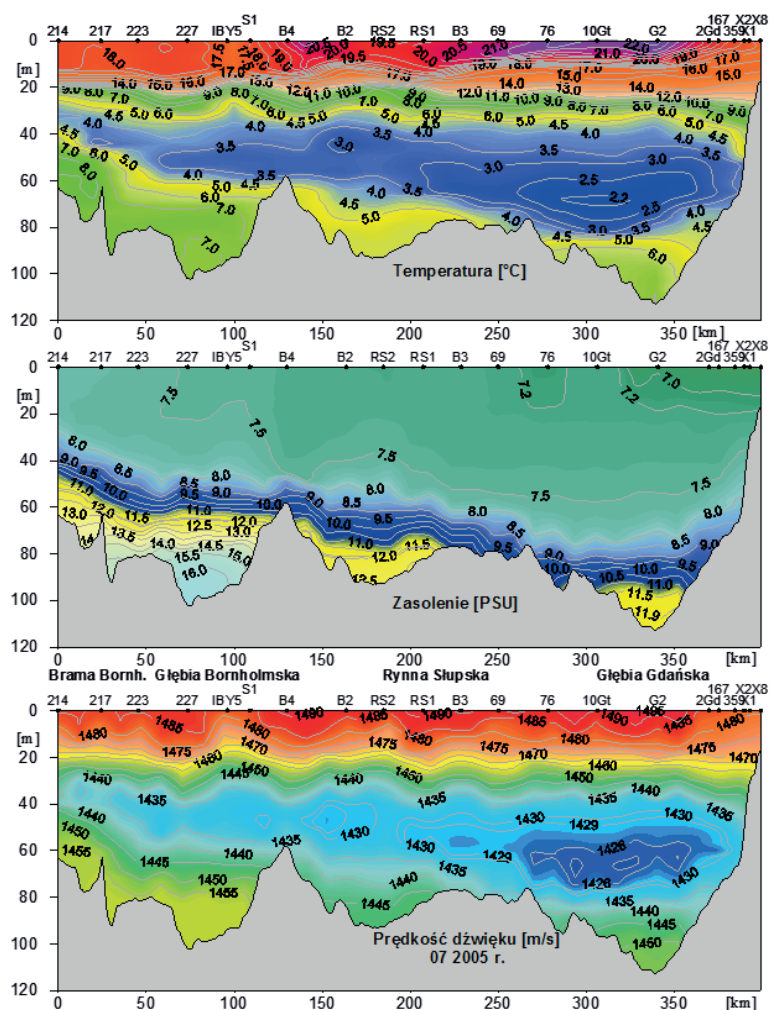

Fig. 3. Vertical distribution of temperature, salinity and sound velocity profile on the hydrological profile though the depths of the southern Baltic sea (July 2005)
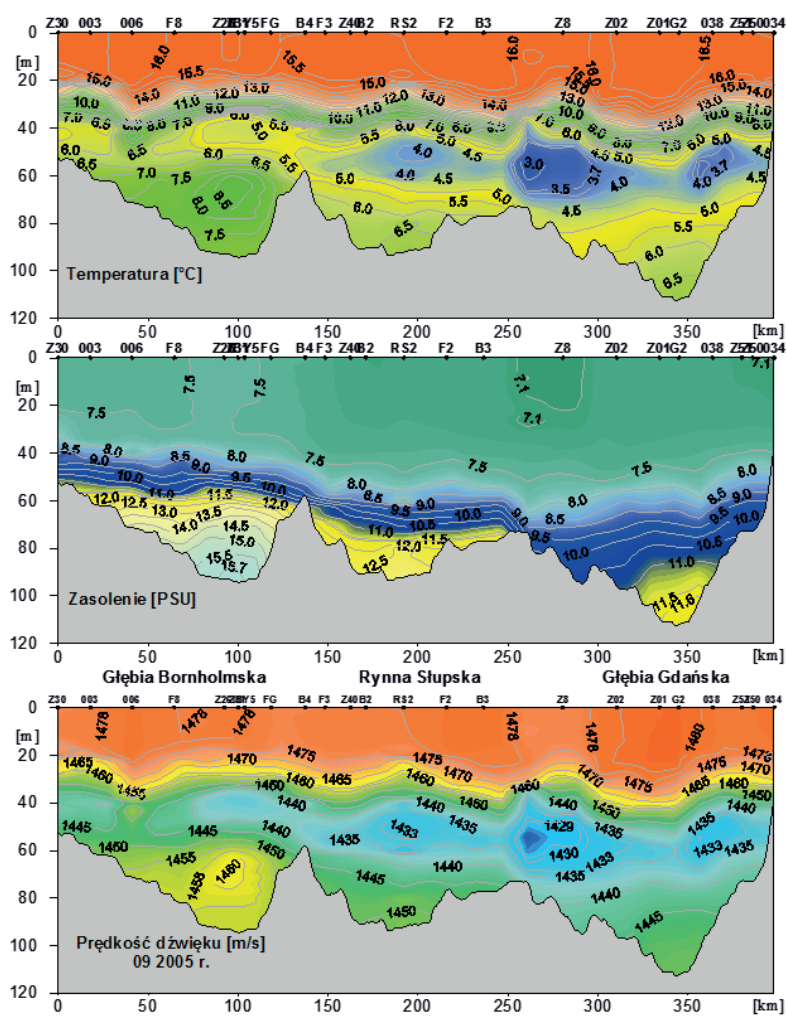

Fig. 4. Vertical distribution of temperature, salinity and sound velocity profile on the hydrological profile though the depths of the southern Baltic sea (September 2005)
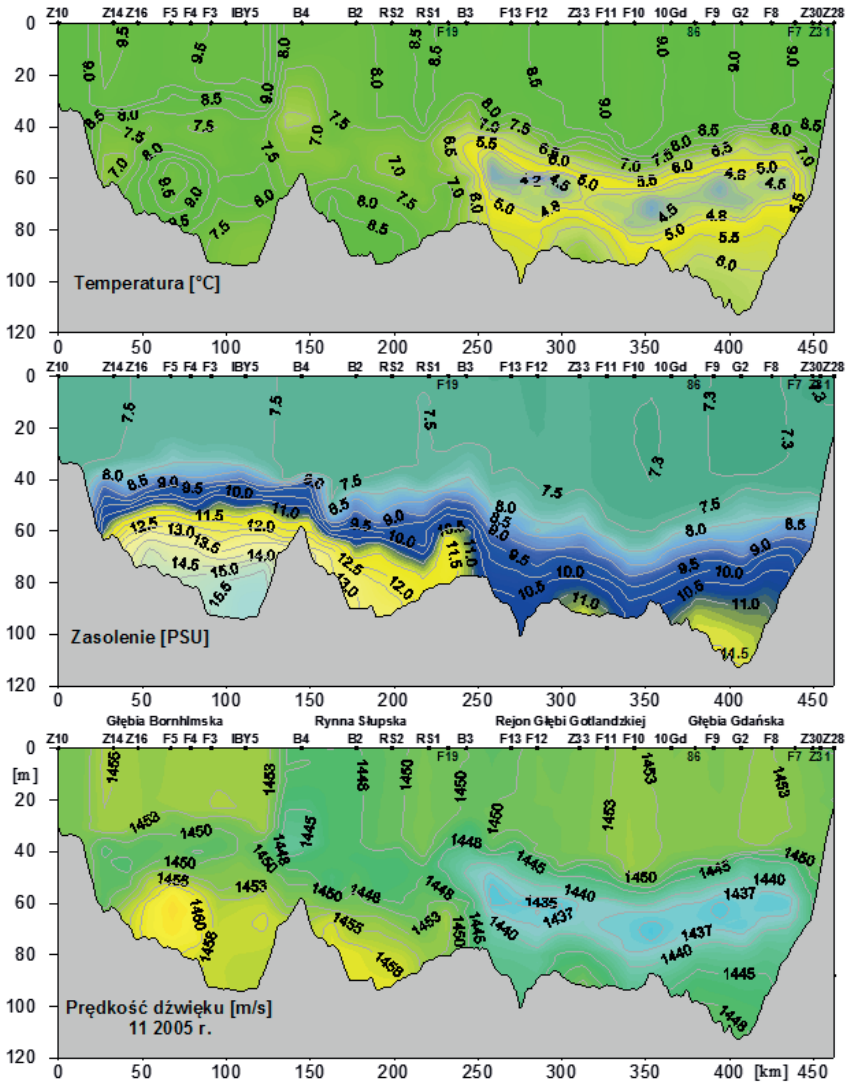

Fig. 5. Vertical distribution of temperature, salinity and sound velocity profile on the hydrological profile though the depths of the southern Baltic sea (November 2005) 
Tab. 1. The values of temperature, salinity and sound velocity at the surface of water in the region of Bornholm Deep at IBY5 station in 2005

\begin{tabular}{|c|c|c|c|c|c|c|c|c|}
\hline Parametr & II & mean & VII & mean & IX & mean & XI & mean \\
\hline temperature [ㅇ] & 3,31 & 2,40 & 17,28 & 16,33 & 16,40 & 15,57 & 9,49 & 8,52 \\
\hline salinity [PSU] & 7,76 & 7,70 & 7,48 & 7,50 & 7,54 & 7,58 & 7,56 & 7,58 \\
\hline Sound velocity[m/s] & 1428,6 & 1424,3 & 1482,4 & 1479,3 & 1479,6 & 1476,9 & 1454,6 & 1450,7 \\
\hline
\end{tabular}

Tab. 2. The values of temperature, salinity and sound velocity at the surface of water in the region of Slupsk Furrow at RS2 station in 2005

\begin{tabular}{|c|c|c|c|c|c|c|c|c|}
\hline Parametr & II & mean & VII & mean & IX & mean & XI & mean \\
\hline temperature [ㅇ] & 2,73 & 2,38 & 21,00 & 16,12 & 16,22 & 15,91 & 8,19 & 8,39 \\
\hline salinity [PSU] & 7,76 & 7,66 & 7,41 & 7,54 & 7,24 & 7,43 & 7,48 & 7,51 \\
\hline Sound velocity[m/s] & 1425,9 & 1424,1 & 1493,7 & 1478,4 & 1478,6 & 1477,7 & 1449,3 & 1450,1 \\
\hline
\end{tabular}

Tab. 3. The values of temperature, salinity and sound velocity at the surface of water in the region of Gdansk Deep at G2 station in 2005

\begin{tabular}{|c|c|c|c|c|c|c|c|c|}
\hline Parametr & II & mean & VII & mean & IX & mean & XI & mean \\
\hline temperature [으] & 3,67 & 2,38 & 22,02 & 16,55 & 16,22 & 15,53 & 9,04 & 8,95 \\
\hline salinity [PSU] & 7,47 & 7,60 & 7,41 & 7,41 & 7,24 & 7,43 & 7,29 & 7,49 \\
\hline Sound velocity[m/s] & 1429,8 & 1424,0 & 1496,7 & 1479,9 & 1478,6 & 1476,5 & 1452,5 & 1452,3 \\
\hline
\end{tabular}

Tab. 4. The values of temperature, salinity and sound velocity at the bottom in the region of Bornholm Deep at IBY5 station in 2005

\begin{tabular}{|c|c|c|c|c|c|c|c|c|}
\hline Parametr & II & mean & VII & mean & IX & mean & XI & mean \\
\hline temperature [ㅇ] & 6,51 & 7,03 & 6,98 & 5,58 & 7,06 & 6,34 & 7,09 & 7,62 \\
\hline salinity [PSU] & 16,54 & 16,50 & 16,13 & 16,80 & 16,01 & 15,87 & 15,95 & 16,44 \\
\hline Sound velocity[m/s] & 1455,1 & 1457,5 & 1456,5 & 1452,7 & 1456,7 & 1453,9 & 1456,7 & 1459,2 \\
\hline
\end{tabular}

Tab. 5. The values of temperature, salinity and sound velocity at the bottom in the region of Slupsk Furrow at RS2 station in 2005

\begin{tabular}{|c|c|c|c|c|c|c|c|c|}
\hline Parametr & II & mean & VII & mean & IX & mean & XI & mean \\
\hline temperature [ㅇ] & 7,65 & 7,06 & 5,78 & 4,81 & 6,64 & 5,50 & 8,75 & 7,33 \\
\hline salinity [PSU] & 13,51 & 12,75 & 12,57 & 13,19 & 13,26 & 12,71 & 12,84 & 13,02 \\
\hline Sound velocity[m/s] & 1455,9 & 1452,4 & 1447,1 & 1443,5 & 1451,7 & 1445,9 & 1459,6 & 1453,8 \\
\hline
\end{tabular}

Tab. 6. The values of temperature, salinity and sound velocity at the bottom in the region of Gdansk Deep at G2 station in 2005

\begin{tabular}{|c|c|c|c|c|c|c|c|c|}
\hline Parametr & II & mean & VII & mean & IX & mean & XI & mean \\
\hline temperature [ㅇ] & 7,13 & 6,43 & 7,01 & 5,42 & 6,71 & 5,29 & 6,41 & 5,66 \\
\hline salinity [PSU] & 12,16 & 11,90 & 12,01 & 12,21 & 11,73 & 11,57 & 11,52 & 11,68 \\
\hline Sound velocity[m/s] & 1452,4 & 1449,1 & 1451,8 & 1445,3 & 1450,2 & 1443,9 & 1448,8 & 1445,5 \\
\hline
\end{tabular}

In the first place, the characteristic of the area of the southern Baltic Sea in the winter months (Fig. 2) will be covered. During this period, the water mixing takes place mainly by the interaction between atmosphere - hydrosphere, which is associated with the occurrence of storms as well as the convection of water movement causing mixing of the water as a function of water depth.

This comes down to determine the temperature in the range $2,6^{\prime} \mathrm{C}$ to about $3,5^{\prime} \mathrm{C}$ layer from the surface of the sea to a depth of 40-50 meters in the region of Bornholm Deep and to a depth of 60-70 meters in the area of Gdansk Deep. The water temperature at the surface in February at the study area was higher than the long-term average in the area of the Gdansk Deep at $1,03^{\prime} \mathrm{C}$. Salinity was not significantly different from the averaged one. As a result of slightly higher temperature, the speed of sound at the surface was greater than the average, the biggest difference in the area of the Gdansk Deep was $5.9 \mathrm{~m} / \mathrm{s}$.

The distribution of the baseline and the salinity in the deep layer in February shows that there was a situation to deal with after the "warm" infusion of water from the North Sea in the preceding season. Still, a clear deficit of salt deep water is visible. In the following months, the salinity at the bottom in the Bornholm Deep and the Gdansk Deep gradually decreased. In Slupsk Furrow, changes in temperature and salinity during the year showed that there was another water supply more saline from Bornholm Deep Slupsk Furrow, which is a typical occurrence at area [20].

In the distribution of the velocity of sound in July, typical of early summer in the Baltic, a water layer is visible at the surface which is characterized by a high speed of sound, reaching more than $1495 \mathrm{~m} / \mathrm{s}$. This is the effect of temperature increase of surface water from about $18{ }^{\circ} \mathrm{C}$ in the region of Bornholm Deep to about $22^{\circ} \mathrm{C}$ in the area of Gdansk Deep. Throughout the 2005 , the surface water temperature was higher than the mean values for each of the months. In July, the surface water reached a depth of about 30 meters (Fig. 3) with a definite main thermocline, which had a base temperature of about $10.0^{\circ} \mathrm{C}$. Below the thermocline, between 30 and $60 \mathrm{~m}$ in the region of Bornholm Deep and 35 and 80 meters in the area of the Gdansk Deep, there was a vast layer of water from the winter with the minimum temperature of 2.1 to $3.5^{\circ} \mathrm{C}$.

In the example, a significant impact on the acoustic conditions had a deeply positioned and poorly developed halocline, which was the result of too little inflow of salt water from the North Sea. The layer of the mixed water with a salinity of approximately constant (7.2-7.5) was very extensive. In July and other months in the area of the Gdansk Deep it reached to a depth of 60 to $70 \mathrm{~m}$.

In the temperature distribution in July (Fig. 3), under the seasonal thermocline, there was a layer of water which is a remnant of the winter with a thickness of 30 meters in the region of Bornholm Deep to about 40 - $50 \mathrm{~m}$ in the area of Gdansk Deep. This water with a temperature of 2.1 to $2.5^{\circ} \mathrm{C}$ in the area of Gdansk Deep to about $3.5^{\circ} \mathrm{C}$ in the region of Bornholm Deep created favorable conditions for the creation of an acoustic channel. Due to the small amount of salt water 
in the deep layer, the layer of cold water was above halocline, at great depth. Minimum in the distribution of the speed of sound defining the sound channel axis was therefore at a depth of about 40 meters in the region of Bornholm Deep to about 70 meters in the area of Gdansk Deep.

In September, the surface water had a temperature of about $15.5-16.0^{\circ} \mathrm{C}$ and the mixed temperature layer formed from the surface to about $20 \mathrm{~m}$, followed by primary thermocline to a temperature of about $7.0{ }^{\circ} \mathrm{C}$ at a depth of $25-30 \mathrm{~m}$ (Fig. 4). In the eastern part of the southern Baltic sea, a layer of cold water with a temperature of $3-4{ }^{\circ} \mathrm{C}$ was still present, which in the region of Slupsk Furrow and Gdansk Deep create the conditions for the creation of an acoustic channel axis at a depth of about 60 meters.

In November, the temperature differences throughout the water column in the western part of the area in question were negligible, but in the area of Gdansk Deep and Gotland Deep still visible was the residual winter water as a layer at a temperature lower than the temperature of the surrounding water masses.

\section{SUMMARY}

The example of changes in hydrological conditions in the wake of the acoustic conditions presented in the article confirms the high complexity of the phenomenon of propagation of acoustic waves in a specific basin, which is the Baltic Sea. The distributions of the speed of sound, the seasonal variation resulting from the cyclical nature of the phenomenon of heat exchange on the border of the sea-atmosphere is evident. However, the course of the phenomenon of the layer of the sea physical properties change is modified by the second factor shaping the acoustic climate of the Baltic Sea, namely the inflow of saline water from the North Sea. In the discussed example, there was a situation described showing a deficit of floodwater in the deep layer. The consequence of this is deeply situated halocline - very poorly developed. Another effect of the lack of denser water in the deep layer is a greater than typically fall of low-temperature water remaining from winter. This water dropped to a depth to which a sufficient heat amount does not reach to heat it. As a result, the acoustic environment differs from the typical. The acoustic channel, which was created in this case is located lower than usually. The lower limit of this channel separates less diverse layers of water, which affects the losses of transmission and efficiency of information transmission.

\section{ACKNOWLEDMENTS}

The paper is elaborated on the basis of hydrological measurements performed by the Sea Fisheries Institute in Gdynia.

The investigation was partially supported by the National Center for Research and Development, Grant No. DOBR/0020/R/ID3/2013/03 and Ministry for Sciences and Higher Education under the scheme of Funds for Statutory Activity of Gdansk University of Technology and Polish Naval Academy.

\section{BIBLIOGRAFIA}

1. Feistel R., Nausch G., Wasmund N.: State and Evolution of the Baltic Sea, 1952-2005. A Detailed 50-Year Survey of Metrology and Climate, Physics, Chemistry, Biology and Marine Environment, Wiley \& Sons, New Jersey, 2008.

2. Fofonoff N.P., Millard R.C. Jr.: Algorithm for computation of fundamental properties of seawater, UNESCO Technical papers in Marine Science No. 44, 1983.

3. Gerdes, F. · Hofmann, H-G. · Jans, W. • Künzel, S. • Nissen, I. • Dol, H.S., Proceedings 3rd International Conference and Exhibition on Underwater Acoustic Measurements - Technologies \& Results - UAM 2009, 21-26 June 2009, Nafplion, Greece.

4. Gloza I.: Identification methods of underwater noise sources generated by small ships, Acta Physica Polonica A, 119, 961-965, 2011.

5. Grelowska G.: The prevailing patterns of the sound speed distribution in the environment of the Southern Baltic, Archives of Acoustics, 25, p. 359-368, 2000.

6. Grelowska G., Kozaczka E., Kozaczka S., Szymczak W.: Underwater noise generated by a small ship in the shallow sea, Archives on Acoustics, 38, 3, 351-356, 2013.

7. G. Grelowska, E. Kozaczka, Nonlinear properties of the Gotland Deep - Baltic Sea, Archives of Acoustics, 40, 4, 2015.

8. Hela I.: The Sound Channel of the Baltic Sea, Geophysica, 5, p.153-161, 1958

9. Holec M., Ratowski J.: Pinowe rozkłady I gradient prędkości dźwieku w południowym Bałtyku I ich bieg roczny, Proc. Of the 25th Open Seminar on Acoustics, 143-151, Poznań 1978.

10. Klusek Z.: The conditions for sound propagation in the southern Baltic, Ed. Institute of Oceanology, 1, 269 pp., Sopot 1991 (in Polish).

11. Klusek Z:: The state of the Baltic Sea acoustic investigations, Proceedings of the International Conference "Underwater Acoustic Measurements: Technologies \& Results"Heraklion, Crete, Greece, 28th June - 1st July 2005.

12. Koppen W.: Grundriss der Klimakunde, Berlin 1931.

13. Kozaczka E., Grelowska G.: Shipping low frequency noise and its propagation in shallow water, Acta Physica Polonica A, 119, 6, 1009-1012, 2011.

14. Kozaczka E., Grelowska G., Szymczak W., Kozaczka S.: Processing data on sea bottom structure obtained by means of the parametric sounding, Polish Maritime Research, 19, 4, 3-10, 2012. 
15. Kozaczka E., Grelowska G., Kozaczka S., Szymczak W., Detection of objects buried in the sea bottom with the use of parametric echosounder, Archives on Acoustics, 38, 1, 99-104, 2013.

16. Łomniewski K., Mańkowski W., Zaleski J.: Morze Bałtyckie, Warszawa 1975.

17. Marszal J., Salamon R.: Detection range of intercept sonar for CWFM signals, Archives of Acoustics, 39, 2, 215-230, 2014.

18. Mietus M., The climate of the Baltic Sea Basin, World Meteorological Organisation, Marine Meteorology and Related Ocaenographics Activities, Rep. No 41, WMO/ TD-No. 999, Geneva 1998.

19. Niros A. Vihma T., Launiainen J.: Marine meteorological conditions and air-sea Exchange processes over the northern Baltic Sea In 1990s, Geophysica, Vol. 38, 1/2, 5987,2002

20. Piechura J., Beszczyńska -Moeller A.: Inflow waters in the deep regions of the southern Baltic Sea: Transport and transformation (corrected version). Oceanologia, 46(1), 113-141, 2004.

21. Piechura J.: Longterm changes in hydrological conditions of the southern Baltic, Bull. Sea Fish. Inst., 128, 1, 45-57, 1993.

22. Pihl J.: Underwater acoustics in the Baltic - a challenging research task, Proceedings of the International Conference "Underwater Acoustic Measurements: Technologies \& Results",Heraklion, Crete, Greece, 28th June - 1st July 2005.

23. Rybak S.A., Serebryany A.N.: Nonlinear internal waves over the inclined bottom: observations with the use of an acoustic profiler, Acoustical Physics, 57, 1, 77-82, 2011.

24. Smedsrud M., Jenserud T., Characterization of long-range time-varying underwater acoustic Communications channels, Acoustics 08, Proceedings of European Conference on Underwater Acoustics, pp. 6097-6102, Paris 2008.

25. Śliwiński A.: Akustyka morza, Enc. Fizyki Współcz., 880885, PWN, Warszawa 1983.

26. The BACC Author Team: Assessment of climate change for the Baltic Sea basin, Springer, Berlin-Heidelberg, 2008.

27. The BACC Author Team, Second assessment of climate change for the Baltic Sea basin, Springer, 2015.

28. Tymański P.: Struktura akustyczna wód południowego Bałtyku, Stud. Mater. Oceanol., 7, 183-189, 1973.

\section{CONTACT WITH THE AUTHOR}

Grażyna Grelowska

gragrelo@pg.gda.pl

Faculty of Ocean Engineering and Ship Technology Gdańsk Univeristy of Technology

11/12 Narutowicza St. 80-233 Gdańsk

Poland 